\title{
Prostate Adenocarcinoma with Neuroendocrine Differentiation
}

National Cancer Institute

\section{Source}

National Cancer Institute. Prostate Adenocarcinoma with Neuroendocrine

Differentiation. NCl Thesaurus. Code C39903.

An invasive prostate adenocarcinoma characterized by the presence of malignant cells that exhibit neuroendocrine differentiation. 